\title{
YOGHURT ANALYSIS WITH ADDITION OF HONEY AND BEE POLLEN BY ULTRASONIC CHARACTERISTICS DURING STORAGE
}

\author{
Tatjana Pavlova ${ }^{1}$, Teodora Valentinova ${ }^{2}$ \\ ${ }^{1}$ Faculty of Technological and Technical Sciences, \\ Saint Kliment Ohridski University of Bitola, Republic of North Macedonia, \\ Dimitar Vlahov bb str., 1400 Veles, Republic of North Macedonia, \\ e-mail: tatjanapavlova15@yahoo.com \\ ${ }^{2}$ Faculty of Technics and Technologies of Yambol, \\ Trakia University of Stara Zagora, Bulgaria \\ 38 Graf Ignatiev str., 8602 Yambol, Bulgaria
}

\begin{abstract}
In the article an analysis of yoghurt with the addition of the bio-active substances bee honey and bee pollen was made. The possibilities for predicting the active acidity of the dairy product by amplitude of ultrasonic signal during storage have been explored. An experimental setup consisting of an ultrasound system, an oscilloscope and a personal computer with ultrasound processing software has been used. The results obtained show that ultrasound characteristics are a suitable tool for yoghurt storage analysis. They implement HACCP recommendations for the use of non-contact measurement methods because they meet the requirement of hygienic measurement standards as they do not affect the structure and composition of yogurt when measured.
\end{abstract}

Keywords: yogurt, storage, bee honey, bee pollen, ultrasonic characteristics.

\section{INTRODUCTION}

The assessment of the quality of dairy products by traditional methods includes expert assessment, chemical and microbiological analyzes. These laboratory methods require appropriate measurement conditions, specialized equipment and qualified personnel [8].

The hygienic measurement of dairy products is one of the important issues set in the Hazard Analysis and Critical Control Point (HACCP) system. Contactless methods are a suitable alternative to traditional methods for measuring milk product parameters at different stages of production. In addition, most of the methods for assessing the quality and condition of dairy products include laboratory tests requiring breakage of the measured material and/or timeconsuming and labor-intensive requiring highly qualified staff [10].

The development of computer equipment and mathematical modeling allows for the development of effective data processing and analysis methods for dairy products obtained with non-contact measuring devices $[9,15]$.

Gan et al. [5] offer a contactless ultrasonic system to monitor the coagulation of fresh milk and a dairy drink with strawberries. A drawback in this study is that the reference measure of active acidity is made with litmus paper. It is necessary to make a precise measurement to establish the relationship between the $\mathrm{pH}$ and the parameters of the ultrasound signal.

Alouache et al. [1] offer an ultrasound system for monitoring coagulation of yogurt. The authors point out that the ultrasound signal speed is an inappropriate parameter for tracing the fermentation process, because in the search for a link between it and the active acidity there is a great uncertainty in the measurements. The disadvantage of the system proposed by these authors is that it uses a contacting method of measurement.

IRITIE Vol. 7, No. 2, 2019 ISSN 1314-8788 (print), ISSN 1314-8796 (online), doi: 10.15547/artte.2019.02.006 


\section{IRTIIL $<>$}

Ipplied Reseirlches in Technicis, Technologies and Bductition

Journal of the Faculty of Technics and Technologies, Trakia University https://sites.google.com/a/trakia-uni.bg/artte/

From a review of available literature, it has been found that the ultrasonic noncontact measurement method is suitable for analyzing dairy products at various stages of their production. By this method the recommendations for hygienic production can be fulfilled. The parameters of the ultrasound signal correlate to a great extent with the physico-chemical and organoleptic characteristics of the dairy products. On the other hand, few published results are related to the use of non-contact ultrasonic sensors to track the change in the quality indicators of dairy products during storage. On the state of the art of technics technology there is a publicity activity related to the use of bio-active substances in dairy products in order to increase their positive effect on human health. The use of ultrasound techniques to analyze these products during storage is poorly affected. The measurement method has the potential because it is a suitable tool in the development of dairy production technologies with a potential positive effect on human health.

The aim of the present work is to analyze the possibility of applying an ultrasonic contactless sensor when assessing the quality of dairy products with added bio-active substances during their storage.

\section{MATERIAL AND METHODS}

The studied dairy products with the addition of bio-active substances are yogurt with added bee products. They are derived from the classical Bulgarian yoghurt technology (BNS 12:2010). For their preparation, lyophilized yeast (Lactina Ltd., Bulgaria) containing local strains of lactic acid microorganisms from the group of Streptococcus thermophilus and Lactobacillus delbrueckii ssp. Bulgaricus. Bee products purchased commercially - honey (complying with EU Council Directive 2001/110/EC) and bee pollen (according to Ordinance No.9, 2005) were used.

Prior to incorporation into yoghurt, bee pollen is treated with UV light in laminar box Nuve MN 090 (Nuve Sanayi Malzemeleri Imalat, Turkey).

The yogurt with addition of bee products have an active acid $\mathrm{pH}$-potentiometrically determined by a pH meter (Model MS 2011, Microsyst, Plovdiv, Bulgaria) equipped with an electrode ( $\mathrm{pH}$ electrode Sensorex, Garden Grove, CA, USA).

To obtain the ultrasound characteristics a laboratory system was developed, developed in the Department of Electrical Engineering, Electronics and Automation of the Faculty of Technology and Technologies of Yambol, Bulgaria [18]. It consists of an ultrasonic system based on the HC-SR04 sensor (Changzhou Manorshi Electronics Co., Ltd.) and Itead Leonardo single board computer (ITEAD Intelligent Systems Co.Ltd), a UNI-T UTD2025CL oscilloscope (TIPA, Ltd.) and a personal computer with software for processing ultrasound features. The distance to receive the features is $35 \mathrm{~cm}$ from the sensor to the subject.

Measurements were made with three replications. All data obtained were processed at a level of significance $\alpha=0,05$.

Residuals analysis was performed. In this analysis, the difference between the real data and the linear model is determined. The resulting differences are then plotted along the vertical axis, and the horizontal values of the independent variable $\mathrm{pH}$. If the resulting graph has a normal distribution around the zero horizontal axis, a first-order model may be used to describe the measured data. In the other case, if the resulting residue graph is nonlinear, it is expedient to describe the experimental data by a second and a higher order model. The sum of all residues is zero [11].

IRTITE Vol. 7, No. 2, 2019 ISSN 1314-8788 (print), ISSN 1314-8796 (online), doi: 10.15547/artte.2019.02.006 


\section{IRTTIE}

Ipplied Reseertrches in Technics, Technologies and Bducation Journal of the Faculty of Technics and Technologies, Trakia University https://sites.google.com/a/trakia-uni.bg/artte/

Models for describing the experimental data are used, which in the available literature [2, 5, $16,17]$ are recommended and used to predict physico-chemical parameters of dairy products by ultrasonic signal parameters. These models are described in Table 1. Three polynomial and two-exponential first and second order models are applied.

Table 1. Models used to describe experimental data

\begin{tabular}{|l|c|c|}
\hline \multicolumn{1}{|c|}{ Model } & Abbreviation & Formula \\
\hline Linear & Poly1 & $y=a x+b$ \\
\hline Polynomial second order & Poly2 & $y=a x^{2}+b x+c$ \\
\hline Polynomial third order & Poly3 & $y=a x^{3}+b x^{2}+c x+d$ \\
\hline Exponential first order & Exp1 & $y=a e^{b x}$ \\
\hline Exponential second order & Exp2 & $y=a e^{b x}+c e^{d x}$ \\
\hline
\end{tabular}

Table 2 describes the errors used for model analysis. In addition to these errors, the regression coefficient $R^{2}$, the sum of squares error (SSE), root mean squares error (RMSE), are used in the analysis. Degrees of freedom DF are defined.

Table 2. Errors for model evaluation for experimental data

\begin{tabular}{|c|c|c|}
\hline Error & \multicolumn{1}{|c|}{ Formula } & \multicolumn{1}{c|}{ Description } \\
\hline $\begin{array}{c}\text { Mean squired } \\
\text { error (MSE) }\end{array}$ & $M S E=\frac{\left\|y-y_{\text {model }}\right\|^{2}}{N_{s}}$ & $\begin{array}{l}\text { Ns - number of } \\
\text { samples; } \| \text { - normed } \\
\text { vector }\end{array}$ \\
\hline $\begin{array}{c}\text { Normed square } \\
\text { root of mean } \\
\text { squared error } \\
\text { (NRMSE) }\end{array}$ & $N R M S E$ & $\begin{array}{l}\text { i=1...n - number of } \\
\text { measurements; } \\
\text { NRMSE is change } \\
\text { from inf - model do } \\
\text { not describe data; } 1- \\
\text { the model describes } \\
\text { the data with sufficient } \\
\text { precision }\end{array}$ \\
\hline $\begin{array}{c}\text { Normed mean } \\
\text { squared error } \\
\text { (NMSE) }\end{array}$ & $N M S E$ & $\begin{array}{l}\text { NMSE is change from } \\
\text { inf - model do not } \\
\text { describe data; } 1-\text { the } \\
\text { model describes the } \\
\text { data with sufficient } \\
\text { precision }\end{array}$ \\
\hline
\end{tabular}

\section{RESULTS AND DISCUSSION}

Data on the change in the amplitude of the ultrasound signal and the active acidity of yoghurt with additives of bee products during the storage period are presented. Models are selected that describe the relationship between these two parameters of yogurt.

Figure 1 shows the amplitude of the ultrasonic signal and the active acidity of yogurt with addition of honey during storage. A decrease in the active acidity values is observed. The same trend shows the amplitude of the ultrasound signal.

IRTIIE Vol. 7, No. 2, 2019 ISSN 1314-8788 (print), ISSN 1314-8796 (online), doi: 10.15547/artte.2019.02.006 


\section{IRTITE}

Ipplied Researl'ches in Technics, Technologies ind Bducation Journal of the Faculty of Technics and Technologies, Trakia University https://sites.google.com/a/trakia-uni.bg/artte/

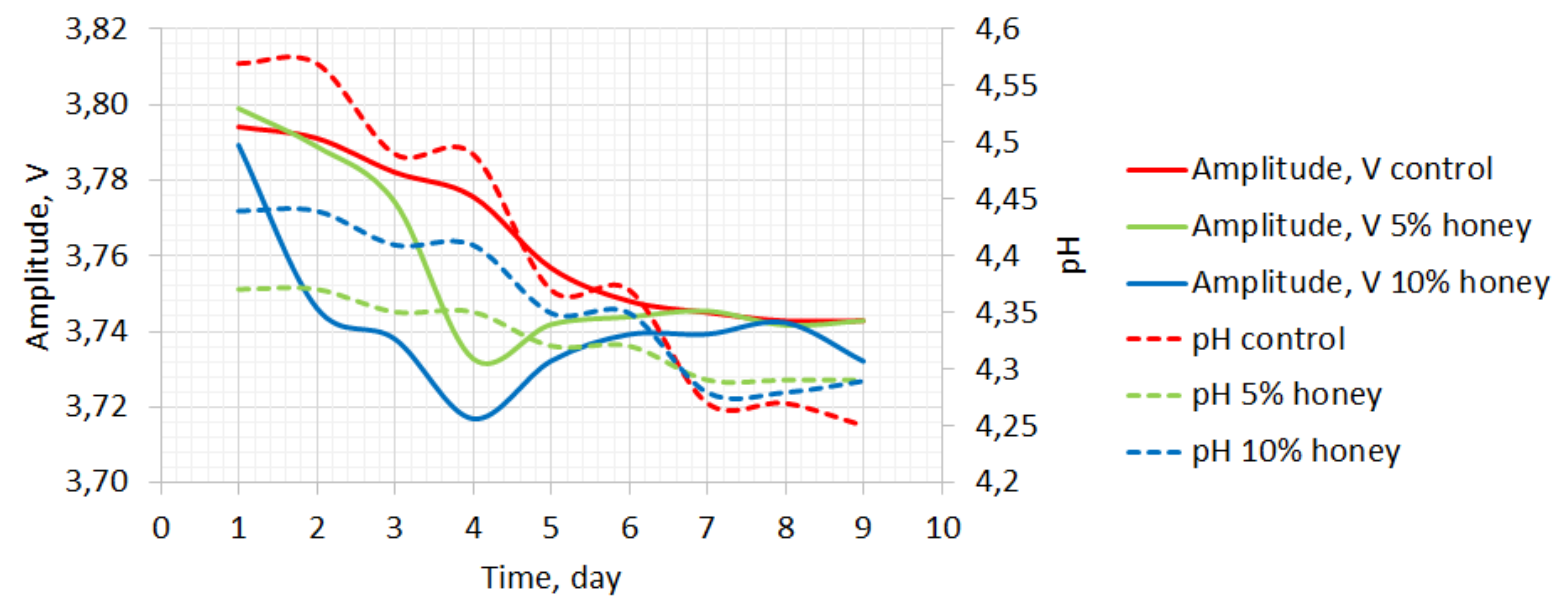

Figure 1. Amplitude of ultrasonic signal and active acidity of yoghurt with addition of honey during storage

Figure 2 shows the amplitude of the ultrasonic signal and the active acidity of yoghurt with addition of bee pollen during storage. As with the previous characteristics, there is a tendency to reduce the active acidity during the storage period of the yoghurt with the addition of bee pollen. The same trend shows the amplitude of the ultrasound signal.



Figure 2. Amplitude of ultrasonic signal and active acidity of yogurt with bee pollen during storage

Figure 3 shows results of a residuals analysis for active acidity and its relationship to the amplitude of the ultrasound signal. According to the above criteria, yoghurt with added honey and the change of the two parameters can be described by a linear model. Various results have been obtained for yoghurt with the addition of bee pollen. It is clear that suitable for describing the relationship between its characteristics are non-linear models of the second and higher order.

IRTTIE Vol. 7, No. 2, 2019 ISSN 1314-8788 (print), ISSN 1314-8796 (online), doi: 10.15547/artte.2019.02.006 


\section{IRTIIE}

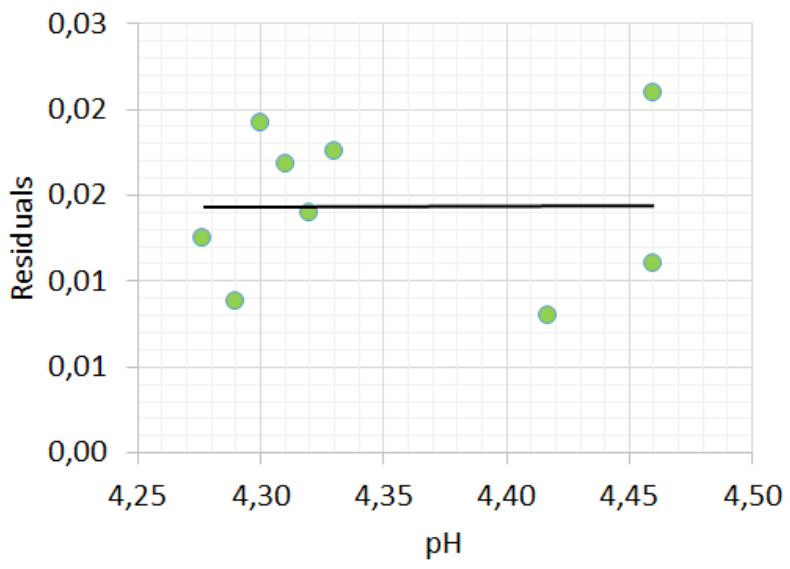

a) Yogurt with honey

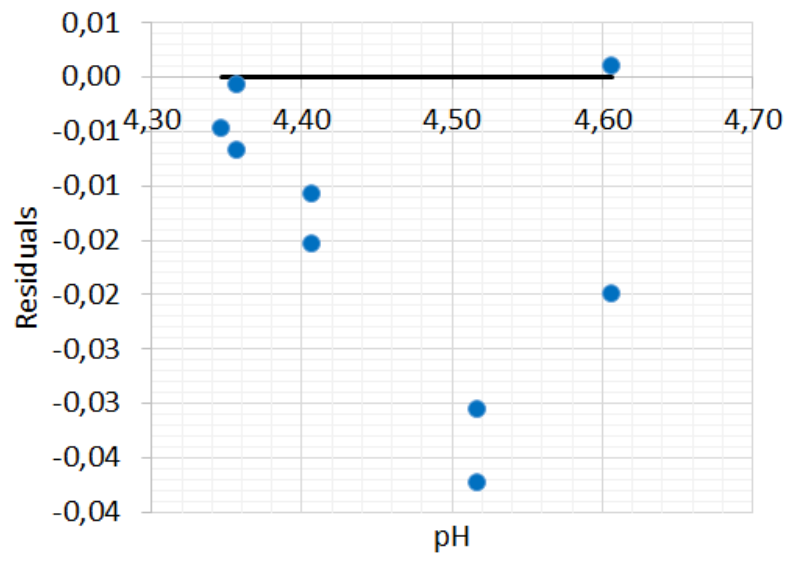

b) Yogurt with bee pollen

Figure 3. Residuals analysis of models

From the residuals analysis it was found that for the description of the experimental data on yoghurt with honey, models of the first order are suitable. From chosen models, a first-order polynomial and a first-order exponential are appropriate. Table 3 provides an analysis of both models. It is seen that they offer 7 degrees of freedom (DF), low error rates SSE and RMSE, up to 0,01 , and regression coefficient $R^{2}=0,94$. The disadvantage of the exponential model is that it is sensitive to variations in the measured data [4]. The data used in the present work are of such character and for this reason a first order polynomial model has been chosen for their description, which has an advantage over exponential for the data used.

Table 3. Evaluation of Models for Yoghurt with Honey

\begin{tabular}{|c|c|c|}
\hline Model & Poly1 & Exp1 \\
\hline $\begin{array}{l}\text { Parameter } \\
\text { a }\end{array}$ & 028 & 270 \\
\hline b & 2,52 & 0,08 \\
\hline DF & 7 & 7 \\
\hline SSE & 0,01 & 0,01 \\
\hline $\mathrm{R}^{2}$ & 0,94 & 0,94 \\
\hline RMSE & 0,01 & 0,01 \\
\hline
\end{tabular}

Experimental data on yoghurt with bee pollen may be described by non-linear models, as determined by the residue analysis. A comparison of the three selected non-linear models second and third order polynomials and second-order exponential is made. As can be seen from the results presented in Table 4, the three models show a regression coefficient $R^{2}$ above 0,8 and low error rates. The degrees of freedom DF are 5 to 6 . Further analysis is needed to select a model describing with sufficient accuracy the experimental data and enabling the accuracy to predict the active acidity by the amplitude of the ultrasound signal.

IRTTE Vol. 7, No. 2, 2019 ISSN 1314-8788 (print), ISSN 1314-8796 (online), doi: 10.15547/artte.2019.02.006 
Table 4. Evaluation of models for yoghurt with bee pollen

\begin{tabular}{|l|r|r|r|}
\hline \multicolumn{1}{|l|}{ Model } & \multicolumn{2}{c|}{ Poly2 } & \multicolumn{1}{c|}{ Poly3 } \\
\hline Parameter & 1,83 & 14,45 & \multicolumn{1}{c|}{ Exp2 } \\
\hline a & $-16,14$ & $-192,60$ & $-0,07$ \\
\hline b & 39,35 & 855,3 & $1,64.10^{-16}$ \\
\hline c & $\mathrm{NaN}$ & -1262 & 7,489 \\
\hline d & 6 & 5 & 5 \\
\hline DF & 0,01 & 0,01 & 0,01 \\
\hline SSE & 0,80 & 0,84 & 0,82 \\
\hline $\mathbf{R}^{2}$ & 0,02 & 0,02 & 0,02 \\
\hline RMSE & & &
\end{tabular}

An assessment of the mean squared errors of the three selected non-linear models has been made. The results of this assessment are shown in Table 5. The second-order exponential model shows a slightly larger error rate compared to the other two polynomial models. Normalized error values are close to 1 , but are lower than those of polynomial non-linear models. Besides the lower indicators of these errors, for the reasons described above, it is not appropriate to use an exponential model to describe experimental data. The two nonlinear polynomial models of the second and third order show very close mean squared errors and the values of the normalized ones are close to 1 . On the other hand, the third order model shows a non-smooth characteristic, which is a prerequisite for the define of a derivative in a certain region of the this characteristic, which is a premise for the model not to be suitable for use in further studies $[6,7,12,13,14]$. The shortcomings of the second-order exponential model and the polynomial model from the third order are missing from the second-order polynomial model. According to the above criteria, a second-order polynomial model is selected to describe the experimental data and predict the active acidity by the amplitude of the ultrasonic characteristics of yoghurt with bee pollen added.

Table 5. Error Values for Model Assessment for Experimental Data

\begin{tabular}{|l|r|r|r|}
\hline & \multicolumn{2}{|c|}{ Model } & \multicolumn{2}{|c|}{ Poly2 } & \multicolumn{2}{|c|}{ Poly3 } \\
\hline Error & 0,002 & 0,002 & 0,004 \\
\hline MSE & 0,557 & 0,560 & 0,254 \\
\hline NRMSE & 0,804 & 0,806 & 0,443 \\
\hline
\end{tabular}

Table 6 describes the models obtained and their solution, which can predict the active acidity of the amplitude of the ultrasound signal Asig measured in V. Equations to predict the amplitude of the ultrasonic signal are output through the online Equation Calculator [3].

Table 6. Solution of models for prediction of active acidity by the amplitude of the ultrasonic signal

\begin{tabular}{|l|c|c|}
\hline \multicolumn{1}{|c|}{ Model } & Equation & Solution \\
\hline Poly1 & $y=0,28 x+2,52$ & $p H_{\text {predicted }}=\frac{25 \cdot A_{\text {sig }}-63}{7}$ \\
\hline Poly2 & $y=1,83 x^{2}-16,14 x+39,35$ & $p H_{\text {predicted }}=\frac{1614 \pm \sqrt{73200 A_{\text {sig }}-275424}}{366}$ \\
\hline
\end{tabular}

IRTIIE Vol. 7, No. 2, 2019 ISSN 1314-8788 (print), ISSN 1314-8796 (online), doi: 10.15547/artte.2019.02.006 


\section{ARTTE $Y$}

Ipplied Reseirlches in Technicis, Technologies and Bductition Journal of the Faculty of Technics and Technologies, Trakia University https://sites.google.com/a/trakia-uni.bg/artte/

\section{CONCLUSION}

Analytical models were developed to indirectly determine the change in basic properties of yogurt with added bee products, depending on the storage time, which can be used to predict a change in properties of these products depending on the storage time.

Because of the nature of the change in residuals, it is not appropriate to use a linear model to predict the change in active acidity of yoghurt with bee pollen. For yoghurt with added honey, it is suitably used on a linear model to predict the change in active acidity by the amplitude of the ultrasound signal.

From the analyzes made, it is found that the first order polynomial model is suitable for predicting the change in the active acidity of yoghurt with honey. To predict this property in yoghurt with bee pollen, a second-order polynomial model is suitable.

Suggested models can be used to develop yoghurt technology with the addition of bee products. They will implement HACCP recommendations for the use of non-contact measurement methods in dairy production.

\section{ACKNOWLEDGEMENTS}

The work is supported by scientific project 5.FTT/ 03.2019 „Possibilities of using bioprotectors in the production of functional foods".

\section{REFERENCES}

[1] Alouache B., A. Touat, T. Boutkedjirt, A. Bennamane. (2015). Monitoring of Lactic Fermentation Process by Ultrasonic Technique. Physics Procedia, Vol.70, pp. 10571060.

[2] Dolatowski, G., P. Pallav, D. Hutchins. (2006). Noncontact ultrasonic quality measurements of food products. Journal of Food Engineering, Vol. 77, pp. 239-247.

[3] Equation Calculator. https://www.symbolab.com/solver/equation-calculator. (available on 25.06.2019).

[4] Five Advantages and Disadvantages of Exponential Smoothing. https://connectusfund.org/5-advantages-and-disadvantages-of-exponential-smoothing. (available on 25.06.2019).

[5] Gan T., P. Pallav, D. Hutchins. (2006). Non-contact ultrasonic quality measurements of food products. Journal of Food Engineering, Vol. 77, pp. 239-247.

[6] Ivanova, D., N. Valov, V. Stoyanov, I. Valova. (2011). Modeling the kinetic curves of apricot drying. Proceedings of the University of Rousse, Vol. 52, Ser. 3.1, pp. 170-174. (in Bulgarian).

[7] Mladenov M. (2015). Complex assessment of the quality of food products by visual image analysis, spectrophotometric and hyper-spectral characteristics. Monograph. University Publishing Center of Rousse University "A. Kanchev", Rousse, 2015. (in Bulgarian).

[8] Mladenov M. (2016). Determination of admissible time of storage of food products by predictive models and neural networks. Proceeding of International Conference Automatics and Informatics, 4-5.10.2016, pp. 77-80.

[9] Nakov, G., N. Ivanova, S. Damyanova, V. Stamatovska, L. Necinova. (2017). Public opinion surveys of consumers for manner of labeling the food product in the Republic of Macedonia. Ukrainian Food Journal, Vol. 6, No.1, ISSN 2313-5891, pp.154-164. 


 Journal of the Faculty of Technics and Technologies, Trakia University https://sites.google.com/a/trakia-uni.bg/artte/}

[10] Ogasawara H., K. Mizutani, T. Ohbuchi, T. Nakamura (2006). Acoustical experiment of yogurt fermentation process, Ultrasonics, Vol. 44, Supp. 22, pp. e727-e730.

[11] Residual Analysis in Regression. https://stattrek.com/regression/residual-analysis.aspx. (available on 24.06.2019)

[12] Stefanova R., A. Georgieva, K. Krastev. (2017). Investigation of the biologically active substances contained in forest fruits for the purpose of using them as a raw material for the production of functional beverages. ARTTE Applied Researches in Technics, Technlogies and Education, Vol.5, No. 4, pp. 312-319.

[13] Stefanova R., A. Georgieva, K. Krastev. (2018). Development of new assortments of phytojams with incorporation of plant ingredients. ARTTE Applied Researches in Technics, Technlogies and Education, Vol.6, No. 2, pp. 312-319.

[14] Tasev, G., K. Krastev. (2011). Exploration of mathematical model for optimization of frequency of diagnosis of the elements of machines. Proceedings of The 11th International Conference, Reliability and statistics in transportation and communication, Latvia, ISBN 978-9984-818-34-4, pp. 115-119.

[15] Vasilev, M., I. Taneva, M. Velikova, R. Mihova. (2016). Interpreting sensory data of cheese "Krema" by Principal component analysis. ARTTE Applied Researches in Technics, Technlogies and Education, Vol. 4, No. 2, ISSN 1314-8796, pp. 139-144.

[16] Yankov K. (2014). Identification of Effective Doses in Binary Mixtures. Proc. Int. Conf. on Information Technologies (InfoTech-2014) St. Constantine and Elena resort, Bulgaria, Sept.18-20, 2014, ISSN 1314-1023, pp. 316-324.

[17] Zlatev Z., I. Taneva. (2017). Physicochemical parameters prediction of yogurt with added honey and bee pollen by ultrasonic characteristics. Innovation and entrepreneurship, Vol. 7, No.1, ISSN 1314-9253, pp. 43-54.

[18] Zlatev, Z., T. Pehlivanova, A. Dimitrova, S. Baycheva, I. Taneva, K. Keremidchieva. (2018). Development of an ultrasonic device for quality evaluation of yogurt. Engineering Review, Vol. 38, No. 3, pp. 279-287.

IRTIIE Vol. 7, No. 2, 2019 ISSN 1314-8788 (print), ISSN 1314-8796 (online), doi: 10.15547/artte.2019.02.006 